\title{
Anatomy of the vasculature supplying hepatobiliary structures and celiac trunk branching patterns in the Thai population
}

\author{
Natcha Nateniyom, Thanasil Huanmanop, Sithiporn Agthong, Vilai Chentanez*
}

\begin{abstract}
Background: Knowledge of the anatomy of the celiac trunk (CT) and arterial supply of the hepatobiliary system is essential for surgical and interventional radiological treatment of upper abdominal diseases.

Objectives: To determine the branching patterns of the CT and variation in origin and type of the right hepatic artery (RHA), left hepatic artery (LHA), and cystic artery (CA).

Methods: The anatomy of the CT in 100 cadavers from Thai adult donors was observed in 3 aspects: its branching pattern, the origin of the RHA and LHA, and the origin of the CA and its relation to the common bile duct (CBD) and common hepatic duct (CHD).

Results: The majority of the CT branching pattern was categorized as the type II classical pattern, which has 3 branches: the left gastric artery (LGA), splenic artery (SA), and common hepatic artery (CHA). The RHA branched from proper hepatic artery in 67 cadavers. The origin of the accessory RHA was either from the abdominal aorta or superior mesenteric artery (SMA), whereas the replaced RHA originated from the CHA, SMA, or CT. The accessory LHA ramified from CHA ( 2 cases) and LGA (1 case). The replaced LHA was found in 30 cadavers and 29 arose from the CHA. The single and double types of CA were found in 94 and 4 cadavers, respectively. In all, 57\% of single CA passed posteriorly and 39\% passed anteriorly to the CBD and CHD.

Conclusions: To lower posttreatment complications, variations in the anatomy and the vascular supply of hepatobiliary structures should be considered.
\end{abstract}

Keywords: celiac artery; gastric artery; hepatic artery; mesenteric artery; superior

Knowledge of the anatomy of the celiac trunk (CT) and arterial supply of the hepatobiliary system is essential for surgical and interventional radiological treatments of upper abdominal diseases. The CT is the main vascular supply of foregut-derived abdominal organs, including the hepatobiliary organs. Standard anatomy texts [1] indicate the CT gives rise to 3 branches: the left gastric artery (LGA), the splenic artery (SA), and the common hepatic artery (CHA). The branching pattern of the $\mathrm{CT}$ has been reported in many populations [2-5], but to our knowledge, not yet fully examined and reported in the Thai population. In 2009, Higashi et al. classified CT branching patterns into 4 types based on the order of branchings [6]. In 1917, 4 types of the branching pattern were documented by Lipshutz based on the order of branching from CT [7]. In 1928, Adachi classified the CT branching into 6 types with more detail of the variations in Japanese population [8]. Michels also reported 6 types of branching patterns, but the detail and order of branchings differed from those of Adachi's classification [9]. Moreover, there were several case reports of different branching patterns such as a common

*Correspondence to: Vilai Chentanez, Department of Anatomy, Faculty of Medicine, Chulalongkorn University, Bangkok 10330, Thailand, e-mail: vilai.ch@chula.ac.th Department of Anatomy, Faculty of Medicine, Chulalongkorn University, Bangkok 10330, Thailand כ Open Access. ๑ 2018 Natcha Nateniyom et al., published by Sciendo. (c) Br-Nc-ND This work is licensed under the Creative Commons Attribution NonCommercial-NoDerivatives 4.0 License. 
trunk of the gastroduodenal artery (GDA) and SA in Chinese [10], hepatogastric and splenomesenteric trunk in Italians [11], and coexistence of a common left gastrophrenic trunk and hepatosplenomesenteric trunk originating from the abdominal aorta (AA) in an Indian case [12].

The CHA plays an important role in hepatobiliary arterial supply. The CHA normally gives 2 branches: the GDA and proper hepatic artery (PHA). The PHA divides into a right hepatic artery (RHA) and a left hepatic artery (LHA) supplying each lobe of the liver. Variations in hepatic arteries have been classified and reported in many types and categories. Michels [13] had described 10 types of variations in hepatic artery based on its origin. Replaced right hepatic artery (rRHA), replaced left hepatic artery (rLHA), accessory right hepatic artery (aRHA), and accessory left hepatic artery (aLHA) were also described. Anatomical detail of the hepatic artery is necessary for hepatic surgery or radiological intervention.

The gallbladder receives its blood supply from hepatic artery via the cystic artery (CA), mostly from the RHA $[13,14]$. The CA is commonly identified in the cystohepatic triangle (Calot's triangle). This triangle is an important landmark for the surgeon when ligating the CA in cholecystectomy. Knowledge of the variation of the CA and its relationship to the surrounded structures would help surgeons to beware of and avoid surgical complications. Therefore, this study was conducted to observe the branching patterns of the CT. Moreover, interesting variations of the hepatic artery and CA were examined.

\section{Materials and methods}

The Institutional Review Board of the Faculty of Medicine, Chulalongkorn University, approved the protocol for the present study (IRB No. 093/61). The branching patterns of the $\mathrm{CT}$ and the origin of hepatic and cystic arteries were observed in cadavers of Thai adult volunteer donors during anatomical dissection classes of medical students. We included 100 formaldehyde-fixed cadavers (52 male, 48 female) without a history of abdominal surgery. Their ages were ranging from 34 and 99 years. During abdominal dissection, the abdominal vasculatures were observed in 3 aspects; first, the branching pattern of the CT; second, the origin of the RHA and LHA including their courses; and third, the origin of the CA and its relation to the common bile duct (CBD) and common hepatic duct (CHD). The data were recorded and observations are reported as percentages as appropriate.

\section{Results}

\section{The branching patterns of the CT}

The CT gave rise to $2-5$ branches. Its branching patterns were classified into 14 types based on the total branches originating from the CT (Table 1). Type I pattern (only 1 cadaver) had 2 branches arising from the CT, which were the SA and CHA. In this type, the LGA directly emerged from the AA

Table 1. The branching patterns of celiac trunk

\begin{tabular}{|c|c|c|c|c|c|}
\hline \multicolumn{2}{|c|}{ Classification } & \multirow{2}{*}{$\begin{array}{l}\text { Branching pattern } \\
\mathrm{SA}+\mathrm{CHA}\end{array}$} & \multirow{2}{*}{$\frac{\text { Number of branches }}{2}$} & \multirow{2}{*}{$\frac{\text { Number of cases }(\mathbf{n}=\mathbf{1 0 0})}{1}$} & \multirow{2}{*}{$\begin{array}{l}\text { Remark } \\
\text { LGA from } A A\end{array}$} \\
\hline Type & 1 & & & & \\
\hline Type & ॥ & $\mathrm{LGA}+\mathrm{SA}+\mathrm{CHA}$ & 3 & 70 & \\
\hline Type & III & $L G A+S A+D P A$ & 3 & 1 & CHA from SMA \\
\hline Type & IV & $\mathrm{SA}+\mathrm{CHA}+\mathrm{LtIP}$ & 3 & 1 & LGA from $A A$ \\
\hline Type & $\mathrm{V}$ & $\mathrm{LGA}+\mathrm{SA}+\mathrm{CHA}+\mathrm{rRHA}$ & 4 & 6 & \\
\hline Type & $\mathrm{VI}$ & $\mathrm{LGA}+\mathrm{SA}+\mathrm{CHA}+\mathrm{DPA}$ & 4 & 4 & \\
\hline Type & VII & $\mathrm{LGA}+\mathrm{SA}+\mathrm{CHA}+\mathrm{SGA}$ & 4 & 1 & \\
\hline Type & VIII & $\mathrm{LGA}+\mathrm{SA}+\mathrm{CHA}+\mathrm{LtIP}$ & 4 & 5 & \\
\hline Type & IX & $\mathrm{LGA}+\mathrm{SA}+\mathrm{CHA}+$ common trunk of LtIP and RtIP & 4 & 2 & \\
\hline Type & $x$ & $\mathrm{LGA}+\mathrm{SA}+\mathrm{CHA}+\mathrm{RtIP}$ & 4 & 4 & \\
\hline Type & $\mathrm{XI}$ & $\mathrm{LGA}+\mathrm{SA}+\mathrm{CHA}+\mathrm{LtIP}+\mathrm{RtIP}$ & 5 & 2 & \\
\hline Type & XII & $\mathrm{LGA}+\mathrm{SA}+\mathrm{CHA}+\mathrm{rRHA}+\mathrm{RtIP}$ & 5 & 1 & \\
\hline Type & XIII & $\mathrm{LGA}+\mathrm{SA}+\mathrm{CHA}+\mathrm{rRHA}+\mathrm{LtIP}$ & 5 & 1 & \\
\hline Type & XIV & $\mathrm{LGA}+\mathrm{SA}+\mathrm{CHA}+\mathrm{DPA}+\mathrm{LtIP}$ & 5 & 1 & \\
\hline
\end{tabular}

AA, abdominal aorta; CHA, common hepatic artery; DPA, dorsal pancreatic artery; LGA, left gastric artery; LtIP, left inferior phrenic artery; rRHA replaced right hepatic artery; RtIP, right inferior phrenic artery; SA, splenic artery; SGA, short gastric artery; SMA, superior mesenteric artery 
(Figure 1). The Type II classical branching pattern of the CT was found in 70 cases and contained 3 branches (LGA, SA, and CHA). Type III pattern consisted of 3 branches, including LGA, SA, and dorsal pancreatic artery (DPA) and was found in 1 case. The CHA in this case had an unusual origin from the SMA and coursed retroportally (Figure 2). Type IV, observed in only in 1 case, had 3 branches, including the SA, CHA, and left inferior phrenic artery (LtIP). The LGA in this case originated directly from the AA as depicted in Type I. Type V to Type $\mathrm{X}$ comprised 3 classical branches and 1 addition branch from the $\mathrm{CT}$. The additional branches were rRHA (Figure 3), DPA, short gastric artery (SGA), LtIP, common trunk of LtIP and RtIP, and RtIP, respectively. Type XI to Type XIV consisted of 3 classical and 2 additional branches. The additional branches were LtIP + RtIP, rRHA + RtIP, rRHA + LtIP, and DPA + LtIP, respectively (Figure 4).

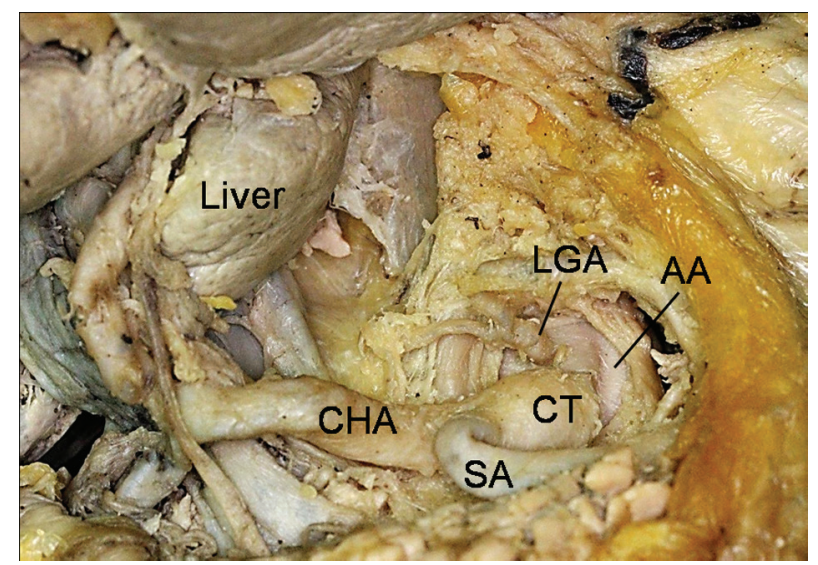

Figure 1. Type I celiac branching pattern. AA, abdominal aorta; $\mathrm{CHA}$, common hepatic artery; CT, celiac trunk; LGA, left gastric artery; $S A$, splenic artery

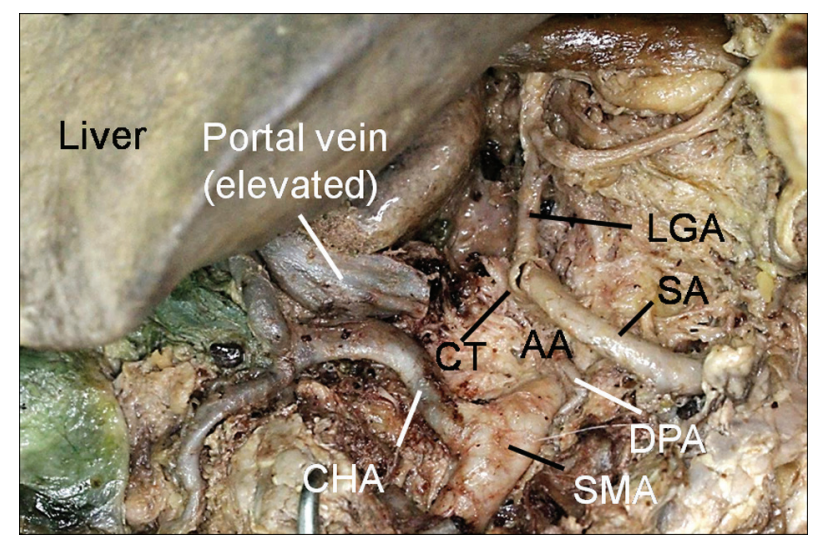

Figure 2. Type III celiac branching patterns. AA, abdominal aorta; $\mathrm{CHA}$, common hepatic artery; $\mathrm{CT}$, celiac trunk; DPA, dorsal pancreatic artery; LGA, left gastric artery; SA, splenic artery; SMA, superior mesenteric artery

\section{The hepatic artery}

The RHA and LHA usually originated from the PHA [13]. In this study, we found some other unusual origins and additional arteries nourishing the liver. The term replaced right hepatic artery (rRHA) or replaced left hepatic artery (rLHA) was used to identify the hepatic artery that arose from origins other than the PHA. The additional arterial branch supplying to each lobe of liver was identified as the aRHA or aLHA.

\section{The origin of the RHA}

In 67 cases, the RHA arose from the PHA without the presence of an aRHA (Table 2). Only 2 cases had both a RHA

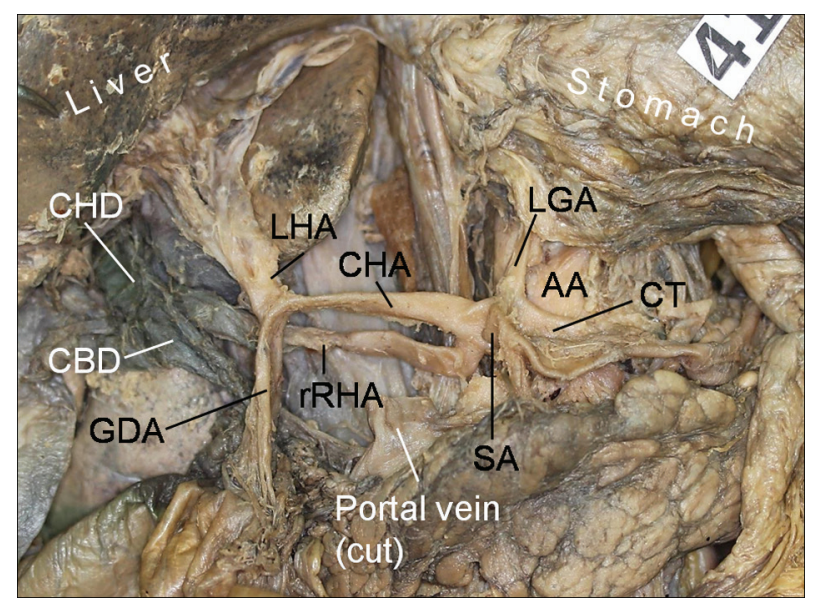

Figure 3. Type $V$ celiac branching patterns. $A A$, abdominal aorta; $\mathrm{CBD}$, common bile duct; $\mathrm{CHA}$, common hepatic artery; $\mathrm{CHD}$, common hepatic duct; CT, celiac trunk; GDA, gastroduodenal artery; LHA, left hepatic artery; LGA, left gastric artery; rRHA, replaced right hepatic artery; SA, splenic artery

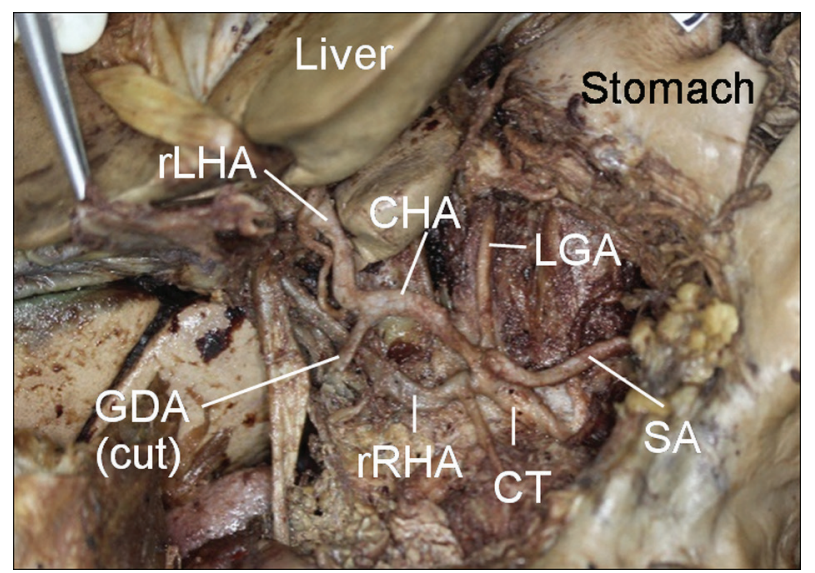

Figure 4. Type XIII celiac branching patterns. CHA, common hepatic artery; $C T$, celiac trunk; GDA, gastroduodenal artery; LGA, left gastric artery; LtIP, left inferior phrenic artery; rLHA, replaced left hepatic artery; rRHA, replaced right hepatic artery; SA, splenic artery 
Table 2. The origin of the RHA and the LHA

\begin{tabular}{|c|c|c|c|c|c|c|c|}
\hline \multirow{3}{*}{ Description } & \multirow{3}{*}{$\begin{array}{l}\text { Number of cases } \\
\qquad n=100\end{array}$} & \multicolumn{6}{|c|}{ Origin } \\
\hline & & PHA & CHA & CT & SMA & AA & LGA \\
\hline & & $\mathbf{n}$ & $\mathbf{n}$ & $\mathbf{n}$ & $\mathbf{n}$ & $\mathbf{n}$ & $\mathbf{n}$ \\
\hline $\mathrm{RHA}$ & 67 & 67 & & & & & \\
\hline $\mathrm{RHA}+\mathrm{aRHA}$ & 2 & & & & 1 (aRHA) & 1 (aRHA) & \\
\hline rRHA & 30 & & 13 & 8 & 9 & & \\
\hline rRHA (from CHA) + aRHA & 1 & & 1 (aRHA) & & & & \\
\hline LHA & 66 & 66 & & & & & \\
\hline $\mathrm{LHA}+\mathrm{aLHA}$ & 3 & & 2 (aLHA) & & & & 1 (aLHA) \\
\hline rLHA & 30 & & 29 & & & & 1 \\
\hline rLHA (from CHA) + aLHA & 1 & & & & & & 1 (aLHA) \\
\hline
\end{tabular}

AA, abdominal aorta; aLHA, accessory left hepatic artery; aRHA, accessory right hepatic artery; CHA, common hepatic artery; CT, celiac trunk; LGA, left gastric artery; LHA, left hepatic artery; PHA, proper hepatic artery; RHA, right hepatic artery; rLHA, replaced left hepatic artery; rRHA, replaced right hepatic artery; SMA, superior mesenteric artery

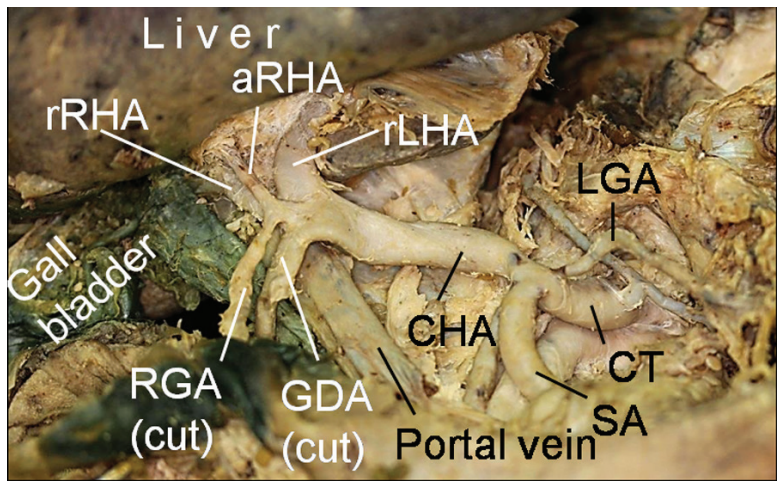

Figure 5. Special variation of the right hepatic artery. Both the rRHA and the aRHA arose from the $\mathrm{CHA}$. aRHA, accessory right hepatic artery; $\mathrm{CHA}$, common hepatic artery; $\mathrm{CT}$, celiac trunk; GDA, gastroduodenal artery; LGA, left gastric artery; RGA, right gastric artery; rLHA, replaced left hepatic artery; rRHA, replaced right hepatic artery; $\mathrm{SA}$, splenic artery

and an aRHA. The aRHA in these cases originated from the AA and the SMA. The existence of the rRHA alone was found in 30 cases. The origins of the rRHA in these cases were from the CHA (13), the SMA (9), and the CT (8). Coexistence of the rRHA and the aRHA was found only in 1 case. Surprisingly, both the rRHA and the aRHA in this case arose from the CHA (Figure 5).

\section{The origin of the LHA}

The LHA was derived from the PHA (66) with absence of an aLHA. Only 3 cases showed both an LHA and an aLHA

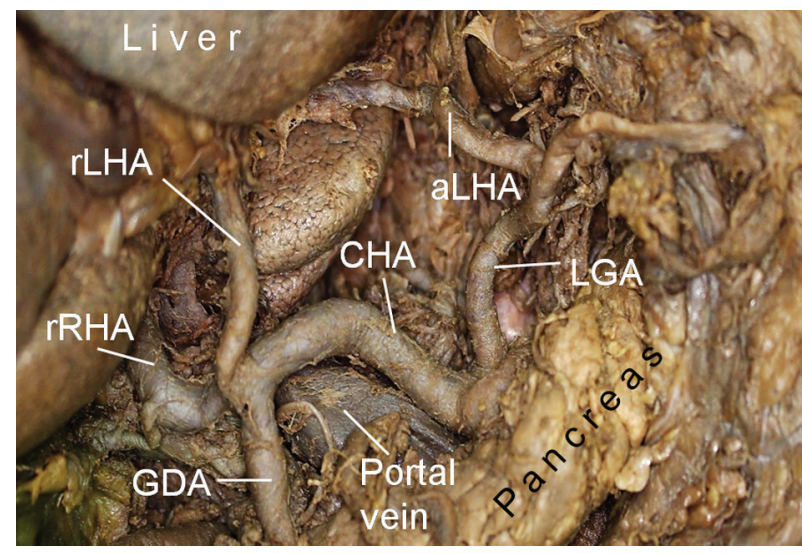

Figure 6. Special variation of the left hepatic artery. rLHA arose from CHA. aLHA arose from LGA. aLHA, accessory left hepatic artery; CHA, common hepatic artery; GDA, gastroduodenal artery; LGA, left gastric artery; rLHA, replaced left hepatic artery; rRHA, replaced right hepatic artery

(LHA + aLHA). The aLHA in these 3 cases originated from the CHA ( 2 cases) and the LGA (1 case). The presence of a rLHA alone was found in 30 cases. Most (29) arose from the CHA. The remainder ramified from the LGA. It is noteworthy that there was 1 case that presented both a rLHA and an aLHA (rLHA + aLHA). The rLHA branched from the CHA, while the aLHA was from the LGA (Figure 6).

\section{Cystic artery}

The CA is commonly a branch from the RHA. It is usually located in Calot's Triangle (cystohepatic or hepatocystic 
Table 3. The origin and type of CA

\begin{tabular}{lccc}
\hline & \multicolumn{3}{c}{ Type of CA } \\
\cline { 2 - 4 } Origin & $\begin{array}{c}\text { Single } \\
\mathbf{n}(\%)\end{array}$ & $\begin{array}{c}\text { Double } \\
\mathbf{n}(\%)\end{array}$ & $\begin{array}{c}\text { Total number of CA } \\
\mathbf{n}=\mathbf{1 0 2}(\%)\end{array}$ \\
\hline RHA & $78(76)$ & $3(3)$ & $81(79)$ \\
rRHA & $9(9)$ & $4(4)$ & $13(13)$ \\
aRHA & $2(2)$ & 0 & $2(2)$ \\
LHA & $1(1)$ & 0 & $1(1)$ \\
CHA & $2(2)$ & 0 & $2(2)$ \\
GDA & $1(1)$ & $1(1)$ & $2(2)$ \\
PHA & $1(1)$ & 0 & $1(1)$ \\
Total number of CA & $94(92)$ & $8(8)$ & $102(100)$ \\
\hline
\end{tabular}

aRHA, accessory right hepatic artery; $\mathrm{CA}$, cystic artery; $\mathrm{CHA}$, common hepatic artery; GDA, gastroduodenal artery; LHA, left hepatic artery; $\mathrm{PHA}$, proper hepatic artery; $\mathrm{RHA}$, right hepatic artery; rRHA, replaced right hepatic artery

triangle). The triangle is bounded by a cystic duct, CHD, and the inferior border of the liver. We attempted to trace the number, origin, and relationship to the CBD and the CHD of the CA. In 2 cases, the CA was accidentally removed. Therefore, data were collected from the remaining 98 cases.

\section{The number and origin of the $C A$}

The single and double types of CA were found in 94 and 4 cases, respectively. Therefore, the origins of the total 102 CAs were examined. As shown in Table 3, 7 origins of the CAs were the RHA, rRHA, aRHA, LHA, CHA, GDA, and PHA. The highest prevalence was from the RHA (79\%). Most of double cystic arteries ramified from the rRHA. Moreover, the GDA gave $1 \mathrm{CA}$ of the double-type CAs (Figure 7).

\section{The relation of the CA to the CBD and the CHD}

Owing to the absence of the CA in 2 of 100 cases, we analyzed the relation of the CA to the CBD and the CHD in the remaining 98 cases (Table 4). A single-type CA was noted in 94 of 98 cases $(96 \%)$ These single-type CA ran either anterior $(39 \%)$ or posterior $(57 \%)$ to the $\mathrm{CBD}$ and $\mathrm{CHD}$. The double-type CAs were identified in 4 of 98 cases. Two cases ran posterior to the $\mathrm{CBD}$ and $\mathrm{CHD}$. One of the remaining 2 cases coursed anterior to the $\mathrm{CBD}$ and $\mathrm{CHD}$, while the other had different relation to both ducts (Figure 7).

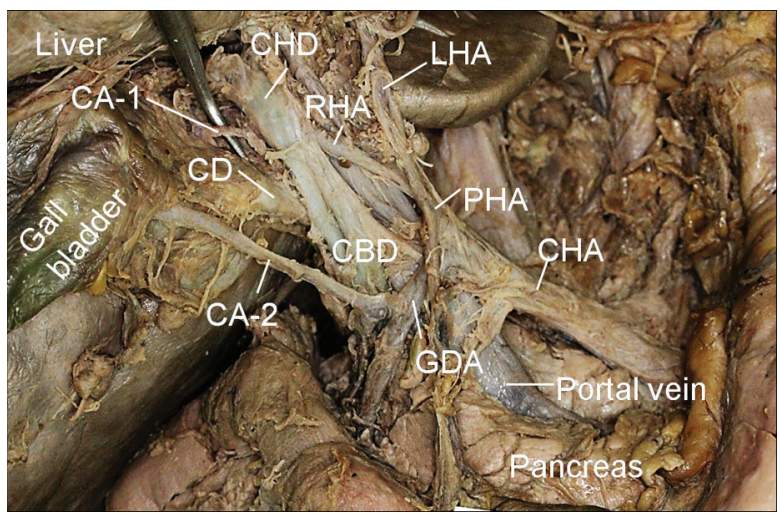

Figure 7. Special variation of the CA. This case had double CAs with different relations to $C B D$ and $C H D$. First $C A(C A-1)$ arose from RHA passing posterior to $C B D$ and $C H D$, while another $C A(C A-2)$ arose from GDA passing anterior to $C B D$ and $C H D$. CA, cystic artery; $C B D$, common bile duct; $C D$, cystic duct; CHD, common hepatic duct; GDA, gastroduodenal artery; $\mathrm{RHA}$, right hepatic artery

\section{Discussion}

The AA is the main arterial supply of intraabdominal organs. There are 2 primitive dorsal aortae in the human embryonic period, which fuse together at the end of fourth week and become the origin of descending aorta. Each primitive dorsal aorta gives rise to multiple of vitelline arteries. After fusion of the primitive dorsal aortae, the vitelline arteries mostly disappear and the rest of them become the origins of thoracic and abdominal arterial supplies (CT, superior mesenteric artery, inferior mesenteric artery) [15]. Variations of abdominal vessels may occur during the embryogenesis due to the persistence or incomplete fusion of some primitive vessels or other factors, such as the malrotation of intestines [1].

The most common branching pattern of CT (Type II) is the classical type with 3 branches. This finding resembles that of previous reports for various ethnicities [3-5]. The incidence of an LGA arising from the AA in Type I (1\%) was less than that reported previously $[7,8]$. Other origins of the LGA are also reported as the SA and CHA [9]. The incidence of CHA arising from SMA in Type III (1\%) from this study is similar to that of previous reports [16-19]. According to Adachi's and Michels' classifications, similar patterns were reported as gastrosplenic trunk and splenogastric trunk with CHA arising from SMA $[8,9]$. These classifications did not indicate the origin of DPA from CT. Type IV was the other type that had 3 branches, the SA, CHA and LtIP from CT, and was found in 1 case. The inferior phrenic artery was previously mentioned as common inferior phrenic trunk arising from splenogastric trunk not directly from CT [3]. Type $\mathrm{V}$ was noted in 6 cases and was the second most common type in this study. 
Table 4. The relation of the $C A$ to the $C B D$ and $C H D$

\begin{tabular}{lcccc}
\hline \multirow{2}{*}{ Classification of the CA } & \multicolumn{4}{c}{ Relation to the CBD and CHD } \\
\cline { 2 - 5 } & Passed anteriorly & Passed posteriorly & $\mathbf{1}$ anterior, 1 posterior & Total number of cases (n = 98) \\
\hline Single & $\mathbf{n}(\%)$ & $\mathbf{n}(\%)$ & $\mathbf{n}(\%)$ & $\mathbf{n}(\%)$ \\
Double & $38(39)$ & $56(57)$ & None & $94(96)$ \\
Total number of case, $\mathrm{n}(\%)$ & $1(1)$ & $2(2)$ & $1(1)$ & $4(4)$ \\
\hline
\end{tabular}

$\mathrm{CA}$, cystic artery; $\mathrm{CBD}$, common bile duct; $\mathrm{CHD}$, common hepatic duct.

The rRHA was the additional branch of this type. There was 1 case with an SGA arising from the $\mathrm{CT}$ as an additional branch.

Normally, the hepatic arterial system starts with the CHA from the CT and then, the CHA gives rise to the PHA. The PHA ramifies into the RHA and LHA, supplying each lobe of the liver. The classification of RHA and LHA in the present study was based on their origins and was categorized into 4 patterns according to the characteristic of each branch. However, from earlier studies [16-21], the classifications of the 2 arteries (RHA, LHA) and their variation patterns were based on Michels' criteria [13]. In Michels' classification, the RHA and LHA were not analyzed separately. By contrast, the present study analyzed the variations of RHA and LHA individually. The incidence of normal pattern of RHA and LHA was lower than previous cadaveric and radiological reports in the Thai population [16-19], but higher than that reported by Michels and lower than that reported by Hiatt et al. [13, 20]. The incidence of the rRHA + aRHA and rLHA + aLHA was 3 times that reported by Hiatt et al. [20]. This inconsistency was probably due to the different definition used for "replaced hepatic artery". Hence, we included the hepatic artery originated from CHA as the rRHA or rLHA, while the study reported by Hiatt et al. classified the hepatic artery from the CHA as the normal RHA and LHA [20]. Variations in origin of replaced and accessory RHA and LHA were noted in the Thai population [16-19]. From previous data, the most common origin of the rRHA was from the SMA (about 3.2\%-13\%) [13, 17-19]. However, in the present study the rRHA was from the CHA (13\%), the SMA (9\%), and the CT (8\%). Moreover, from the present study, the rLHA was found in $31 \%$ of individuals, and originated from the CHA (30\%) and the LGA (1\%). By contrast, in previous studies, the origin of rLHA was solely from the LGA, which was confirmed by embryogenesis [21]. The incidence of an aRHA and an aLHA resembled that in a previous report of Thais [16], but was lower than that reported for individuals with other ethnicities $[13,20]$. The origins of these arteries were from the CHA, SMA, and AA for the aRHA, but from the CHA and LGA for aLHA (Table 2) as consistent with previous reports $[13,16,20]$.

The present study analyzed the CA in cadavers from Thai adults in 3 aspects: (1) the type of CAs, (2) the origin of the CA, and (3) the relation of the $\mathrm{CA}$ to the $\mathrm{CBD}$ and the CHD. The incidence of a single CA and of a double CA was consistent with that in previous reports, but the existence of a double CA was less $[13,14,16,22]$. The most common origin of the CA from the RHA (79\%) in the present study was similar to that reported previously $[14,22,23]$. The second most common origin of the CA was from the rRHA (13\%). The other origins of the CA were from the aRHA, LHA, CHA, PHA, or GDA. The origin of the CA from the SMA was reported previously for a Thai population [22] and in studies of individuals with other ethnicities [14, 23].

The relationship of the CA to the CBD and CHD were classified into 2 types. Typically, the CA ran within cystohepatic triangle and coursed posteriorly to the CBD and CHD [13, $14,22]$, which was also observed 59\% (Table 4) of individuals in the present study. In cases of double CA, both arteries might pass anteriorly, posteriorly, or separating them.

\section{Conclusions}

Surgical and interventional radiology have important roles for the treatment of abdominal diseases. To minimize the posttreatment effects and complications, variations in hepatobiliary vascular anatomy should be considered. The anatomy of the vascular supply to the hepatobiliary system in cadavers from Thai adult donors examined in the present study, had some features that were distinct from previous studies. The branching patterns were classified into 14 types. The classical branching pattern remained the most common, while we observed some new additional branches from the CTs. Origins of the RHA and LHA were diverse. The CA had variations in type, origin, and in relation to its surrounding hepatobiliary structures. 
Author contributions. NN, TH, SA, and VC contributed substantially to the conception and design of this study. All authors dissected and collected the data. NN and VC analyzed and interpreted data. All authors were involved in drafting and critical revision of the manuscript, approved the final version submitted for publication, and take responsibility for the statements made in the published article.

Acknowledgments. The authors thank Prim Akkarawanit, Peerada Areenich, Nattapat Tangchitchareon, and Pakapoom Sukswai, who helped in dissection of cadavers and recording the data. The present work was presented in part as a poster at the 41st Annual Conference of the Anatomy Association of Thailand (AAT41), 2018 May 23-25, Cha-am, Phetchaburi, Thailand. Natcha Nateniyom, Thanasil Huanmanop, Sithiporn Agthong, Vilai Chentanez. Surgical anatomy of vascular supplying hepatobiliary structures and celiac trunk branching patterns in Thai population [PP 58, AAT43]. We did not receive any specific grant for this research from any funding agency in the public, commercial, or not-for-profit sectors.

Conflict of interest statement. The authors have each completed and submitted an International Committee of Medical Journal Editors Uniform Disclosure Form for Potential Conflicts of Interest. None of the authors disclose any conflict of interest.

\section{References}

[1] Standring S, Barley NR, Collins P, Crussman AR, Gatzoulis MA, Healy JC, et al. Grey's anatomy. The anatomical basis of clinical practice. Edinburgh: Elsevier; 2008.

[2] Vandamme JP, Bonte J. The branches of the celiac trunk. Acta Anat. $1985 ; 122: 110-4$

[3] Venieratos D, Panagouli E, Lolis E, Tsarakis A, Skandalakis P. A morphometric study of the celiac trunk and review of the literature. Clin Anat. 2013; 26:741-50.

[4] Panagouli E, Venierators D, Lolis E, Skandalakis P. Variations in the anatomy of celiac trunk: a systematic review and clinical implications. Ann Anat. 2013; 195:501-11.

[5] Song S-Y, Chung JW, Yin YH, Jae JH, Kim H-C, Jeon UB, et al. Celiac axis and common hepatic artery variations in 5002 patients: systematic analysis with spiral CT and DSA. Radiology. 2010; 255:278-88
[6] Higashi N, Shimada H, Simamura E, Hatta T. [Branching patterns of the celiac artery as the hepato-gastro-splenic trunk]. Kaibogaku Zasshi. 2009; 84:7-10. [in Japanese, English abstract]

[7] Lipshutz B. A composite study of the celiac axis artery. Ann Surg. 1917; 65:159-69.

[8] Adachi B. Das arteriensystem der Japaner, Vol 2. Kyoto: Maruzen Publishing Co; 1928, p. 20-71. [in German]

[9] Michels NA. Blood supply and anatomy of the upper abdominal organs: with a descriptive atlas. Philadelphia: Lippincott; 1955.

[10] Li J, Ren ZF. Gastroduodenal-splenic trunk: an anatomical vascular variant. Rom J Morphol Embryol. 2011; 52:1385-7.

[11] Mariani GA, Maroni L, Bianchi L, Broccoli A, Lazzarini E, Marchegiani G, et al. Hepato-gastric and spleno-mesenteric arterial trunks: anatomical variation report and review of literature. Ital J Anat Embryol. 2013; 118:217-22.

[12] Prasanna LC, Alva R, Sneha GK, Bhat KMR. Rare variations in the origin, branching pattern and course of the celiac trunk: report of two cases. Malays J Med Sci. 2016; 23:77-81.

[13] Michels NA. Newer anatomy of the liver and its variant blood supply and collateral circulations. Am J Surg. 1966; 112:337-47.

[14] Mooseman DA. Where and how to find the cystic artery during cholecystectomy. Surg Gynecol Obstet. 1975; 141:769-72.

[15] Schoenwolf GC, Bleyl SB, Brauer PR, Francis-West PH, editors. Larsen's human embryology. 4th ed. Churchill Livingstone/Elsevier; Philadelphia; 2009.

[16] Sreesai M, Chittmittrapap S. A study of the surgical anatomy of hepatic arteries. Chula Med J. 1986; 30: 313-24.

[17] Musiksilp S, Udomsawaengsup S, Panichabhongse V. Anatomical variations of extrahepatic hepatic artery in Thai people, 29th Annual Congress of the Royal College of Surgeons of Thailand. Thai J Surg. 2004; 25:93.

[18] Arjhansiri K, Charoenrat P, Kitsukjit W. Anatomical variations of the hepatic arteries in 200 patients done by angiography. J Med Assoc Thai. 2006; 89:S161-8.

[19] Prabhasavat K, Homgade C. Variations of hepatic artery by 3-D reconstruction MDCT scan of liver in Siriraj Hospital. J Med Assoc Thai. 2008; 91:1748-53.

[20] Hiatt JR, Gabbay J, Busuttil RW. Surgical anatomy of hepatic arteries in 1000 cases. Ann Surg. 1994; 220:50-2.

[21] Skórzewska A, Stajgis P, Grzymisławska M, Rojewska M, Krajecki M. Rare variations of hepatic arteries in association with variable origin of gastroduodenal artery found in multidetector computed tomography angiography. Folia Morphol (Warsz). 2014; 73:531-5.

[22] Chittmittrapap S, Sreesai M, Dhanvarjör P. Surgical anatomy of the cystic artery. Chula Med J. 1985; 29:1207-17. [in Thai, English abstract]

[23] Andall RG, Matusz P, du Plessis M, Ward R, Tubbs RS. The clinical anatomy of cystic artery variations: a review of over 9800 cases. Surg Radiol Anat. 2016; 38:529-39. 